ORIGINAL ARTICLE

\title{
Office Hysteroscopy and Pipelle Endometrial Biopsy versus Diltation and Curettage in Diagnosis of Endometrial pathology in women with perimenopausal bleeding.
}

\author{
Ahmed Abd-Elwahed Abd-Elmageed ${ }^{\mathrm{I} *}$, Ashraf Mohamed Nasr ${ }^{\mathrm{I}}$, Tarek Mohamed \\ Elbehiedy ${ }^{\mathrm{I}}$, Ahmed Mahmoud Abdou ${ }^{\mathrm{I}}$ \\ I: Obstetrics and Gynecology department, Faculty of medicine, Zagazig university, Zagazig , El \\ Sharkia, Egypt
}

\section{*Corresponding Author}

Ahmed Abd-Elwahed AbdElmageed Ahmed

Obstetrics and Gynecology department, Faculty of medicine, Zagazig university, Zagazig, El Sharkia, Egypt. E-mail: ahmedwahed1391@yahoo.com

Submit Date: 04-08-2019

Revise Date: 23-08-2019

Accept Date: 27-08-2019
Background: Abnormal uterine bleeding(AUB) is a common gynecologic complaint. Some authors recommend endometrial sample in diagnosing AUB by pipelle method and hysteroscopy. However, this need more investigations to be proven. The aim of the study was to compare between the histopathological findings of Pipelle endometrial biopsy, office hysteroscopy and dilatation and curettage (D\&C) (the gold standard). Methods: This cross-sectional study was carried out in outpatient clinic of Obstetrics \& Gynecology Department at Zagazig University Hospitals, Zagazig, Sharkia, Egypt, from July 2018 till March 2019. Fourty three cases were included. All women were present with perimenopausal bleeding. Full history was taken, office hysteroscopy was done, pipelle endometrial aspiration after 2 hours, D\&C within 48 hours then tissue samples were placed into bottles containing formalin $10 \%$ and sent for histopathological examination and finally the results were compared. Results: Histopathological examination of endometrial samplings by pipelle method revealed endometrial hyperplasia in 10 cases, hyperplasia with atypia in 4 cases, polyp in 0 cases, endometritis in 3 cases.Also, hysteroscopy revealed endometrial hyperplasia in 8 cases, hyperplasia with atypia in 2 cases, polyp in 5 cases, endometritis in 2 cases.These were correlated with histopathological findings of conventional D and C sampling method which showed that endometrial sampling by pipelle method and hysteroscopy had a high sensitivity and spesificity in diagnosing abnormal endometrium.Conclusion: Pipelle endometrial sampling and hysteroscopy are an easy and safe methods of tissue diagnosis which can be done as an out-patient procedures and without anaesthesia.

Keywords: Pipelle endometrial sampling; hysteroscopy; D\&C; AUB.

\section{INTRODUCTION}

$\mathrm{T}$ he abnormal uterine bleeding (AUB) is a major clinical problem among women in the reproductive, perimenopausal and postmenopausal age groups. The AUB requires exclusive assessment, to exclude atypical endometrial hyperplasia and carcinoma [1]. Because of its broad range of differential diagnosis,the diagnosis of abnormal uterine bleeding can be quiet challenging ,despite adetailed history, various November. 2020 Volume 26 Issue 6 blood tests , and a thorough pelvic examination often involving transvaginal ultrasonography, the cause of bleeding is established in only 50 to $60 \%$ of the cases [2]. Histopathological examination of endometrial tissue remains the mainstay in the evaluation of AUB. In the recent scenario, endometrial sampling is being obtained by various invasive and non invasive techniques such as pipelle technique, dilatation and curettage (D\&C) and hysteroscopic guided biopsy [3].The advantages of non 
invasive office procedures like pipelle endometrial sampling has posed a challenge to the whole range of conventional invasive techniques. It is now widely accepted by the clinicians and patients, since they are safe and economical. The conventional modalities like $\mathrm{D} \& \mathrm{C}$ and hysteroscopic guided biopsy may require hospitalisation and anaesthesia [3]. Pipelle endometrial sampling has been gaining popularity as the most convenient method of sampling endometrial lining in the recent times. It can sample about $5-15 \%$ of the total endometrial surface area [4]. It is especially useful in global lesions involving in large surface area of the endometrium than in focal lesions [5]. Hysteroscopy is an accurate and minimally invasive method for the evaluation of uterine cavity. It is a dynamic test and allows a direct visualization of the endometrium, revealing the nature, location,shape, size and vascular pattern of any uterine cavity abnormalities. The main advantage of hysteroscopy is that biopsies can be taken at the same time with great safety, which improves the diagnostic accuracy. Also, its "see and treat" potential provides higher patient satisfaction.Hysteroscopy is increasingly replacing $\mathrm{D} \& \mathrm{C}$ for the evaluation of AUB [6]. The D\&C is the most conventional method of endometrial sampling since many decades. Though, it offers a high degree of sensitivity in diagnosis of endometrial lesions, the associated surgical risks, postoperative pain, higher costs due to hospitalization and anaesthesia have necessitated the search for a suitable substitute which is simpler, cheaper, non invasive, free of complications and offers good diagnostic accuracy [4]. Previous studies have raised concern in regard to adequacy of endometrial sample in diagnosing endometrial hyperplasia by pipelle method and hysteroscopy[7]. Hence, the present study was proposed to evaluate the efficacy of pipelle sampling and hysteroscopy in diagnosing endometrial pathologies in patients with perimenopausal abnormal uterine bleeding in comparison with gold standard D\&C method.

\section{METHODS}

This cross-sectional study was carried out in outpatient clinic of Obstetrics \& November. 2020 Volume 26 Issue 6
Gynecology Department at Zagazig University Hospitals, Zagazig, Sharkia, Egypt, from July 2018 till March 2019. Fourty three cases were included. All women were aged 40 to 55 years and presented with perimenopausal bleeding. Our exclusion criteria were pregnant women,women with sever vaginal bleeding, gross evidence of cervical malignancy, acute inflammatory disorder of the genital tract, fibroid uterus,bleeding disorder, anticoagulant treatment and women under hormonal therapy.

After including cases that met the eligibility criteria and obtaining written informed consent, we took Full history including personal, present, past, family, obstetric, contraceptive and menstrual history. Exclusion of pregnant women. Full lab.investigations and transvaginal ultrasound were done.

Office hysteroscopy was done with good visualization of the cavity systematically, first the fundus, anterior, posterior and lateral walls of the uterus ending by visualization of the uterotubal junctions and endometrial sample was taken from any suspected area of endometrium and placed into a bottle with formalin $10 \%$ and labelled A. The endometrial sampling was performed by the Pipelle device. After 2 hours, the Pipelle was introduced without performing cervical dilatation and withdrawn outside the uterus with a rotatory movement to get the sample which placed into a bottle with formalin $10 \%$ and labeled B. The patients were then transferred to the operative theatre within 48 hours for $\mathrm{D} \& \mathrm{C}$ and the obtained sample after D\&C was placed also into a bottle with formalin $10 \%$ labeled as sample C. Three samples were sent to a pathologist, who was blinded to the methods of sampling and patients' medical history for histopathology assessment. The histopathology reports of the Pipelle sample and hysteroscopy were compared with that of the D\&C sample and the $\mathrm{D} \& \mathrm{C}$ report was considered as the gold standard.

Written informed consent was obtained from all participants and the study was approved by the research ethical committee of Faculty of Medicine, Zagazig 
University. The work has been carried out in accordance with The Code of Ethics of the World Medical Association (Declaration of Helsinki) for studies involving humans.

Statistical analysis was performed using Statistical Program for Social Science (SPSS) version 25.0 for windows (SPSS Inc., Chicago, IL, USA), NCSS 12 for windows (NCSS LCC., Kaysville, UT, USA). Quantitative data of normal distribution were expressed as mean \pm standard deviation (Goldstein and Lumsden), whereas median and range (minimum - maximum) were calculated for not normally distributed quantitative data. Qualitative data were expressed as frequency and percentage. The following tests were done; Mann Whitney $\mathrm{U}$ test is used to compare differences between two independent groups when the dependent variable is continuous, but not normally distributed, Chi-square (X2) test also called Pearson's chi-square test or the chi-square test of association, is used to discover if there is a relationship between two categorical variables, Fisher Exact test is a test of significance that is used in the place of chi square test in 2 by 2 tables, especially in cases of small samples and A one-way analysis of variance (ANOVA) was used when comparing among more than two means if data is normally distributed.

\section{RESULTS}

The age of the study population was ranged from 42 to 53 years with a mean 49.0 \pm 2.83 years and BMI was ranged from 25 to $45 \mathrm{~kg} / \mathrm{m} 2$ with a mean $33.46 \pm 5.1$ $\mathrm{kg} / \mathrm{m} 2$.(Table 1)

This table showed that the pathological findings of patient examined obtained by endometrial curettage revealed normal in 25 cases $(58.1 \%)$, endometrial hyperplasia in 9 cases $(20.9 \%)$, hyperplasia with atypia in 3 cases (6.95\%), polyp in 4 cases $(9.3 \%)$, endometritis in 2 cases (4.65 $\%$ ). While, pipelle revealed normal in 26 cases $(60.5 \%)$ and the most common endometrial lesion was endometrial hyperplasia $(23.25 \%)$ but it cannot detect any polyp (0\%). Also, hysteroscopy revealed normal in 26 cases $(60.5 \%)$ and the most common endometrial lesion was endometrial hyperplasia (18.6 $\%$ ).(Table 2)

This table showed very good agreement between hysteroscopy and endometrial curettage (kappa $=0.83)$ and between pipelle and endometrial curettage (kappa $=0.83$ ) in detection of endometrial abnormality and showed that pipelle and hysteroscopy had the same sensitivity $(94.4 \%)$ and specificity (100.0\%) in detection of endometrial abnormality.(Table 3)

This table showed good agreement between hysteroscopy and endometrial curettage (0.79) and very good agreement between pipelle and endometrial curettage (0.81) in detection of endometrial hyperplasia.Also, pipelle had sensitivity $(100.0 \%)$ and specificity $(97.06 \%)$ but hysteroscopy had sensitivity $(88.89 \%)$ and specificity $(100.0 \%)$.(Table 4)

This table showed good agreement between hysteroscopy and endometrial curettage (0.76) and very good agreement between pipelle and endometrial curettage (0.81) in detection of endometrial hyperplasia with atypia.Also, pipelle had sensitivity $(100.0 \%)$ and specificity $(97.5 \%)$ but hysteroscopy had sensitivity $(66.67 \%)$ and specificity (100.0\%).(Table 5)

This table showed good agreement between hysteroscopy and endometrial curettage (0.74) in detection of endometrial polyp.Also, hysteroscopy had sensitivity $(100.0 \%)$ and specificity (97.44\%). While, pipelle didn't detect any polyp.(Table 6)

This table showed very good agreement between hysteroscopy and endometrial curettage (1.0) and between pipelle and endometrial curettage $(0.81)$ in detection of endometritis.Also, pipelle had sensitivity (100.0\%) and specificity (97.56\%) but hysteroscopy had sensitivity (100.0\%) and specificity (100.0\%).(Table 7) 
Table 1. Distribution of studied group according to Age and BMI.

\begin{tabular}{|c|c|c|}
\hline & Mean \pm SD & Median (Range) \\
\hline Age & $49.0 \pm 2.83$ & $49.0(42-53)$ \\
\hline BMI & $33.46 \pm 5.1$ & $33.0(25-45)$ \\
\hline
\end{tabular}

Table 2. Pathology of endometrial tissue obtained by endometrial curettage, pipelle and hysteroscopy (endometrial curettage is the gold standard).

\begin{tabular}{|l|c|c|c|c|c|c|}
\hline & $\begin{array}{c}\text { endometrial } \\
\text { curettage }\end{array}$ & \multicolumn{2}{|c|}{ Pipelle } & \multicolumn{2}{c|}{ Hysteroscopy } \\
\hline & $\mathrm{N}$ & $\%$ & $\mathrm{~N}$ & $\%$ & $\mathrm{~N}$ & $\%$ \\
\hline Normal & 25 & 58.1 & 26 & 60.5 & 26 & 60.5 \\
\hline Endometrial hyperplasia & 9 & 20.9 & 10 & 23.25 & 8 & 18.6 \\
\hline Hyperplasia with atypia & 3 & 6.95 & 4 & 9.3 & 2 & 4.65 \\
\hline Polyp & 4 & 9.3 & 0 & 0 & 5 & 11.6 \\
\hline Endometritis & 2 & 4.65 & 3 & 6.95 & 2 & 4.65 \\
\hline Total & 43 & 100 & 43 & 100 & 43 & 100 \\
\hline
\end{tabular}

Table 3. Validity of hysteroscopy and Pipelle in detection of abnormality.

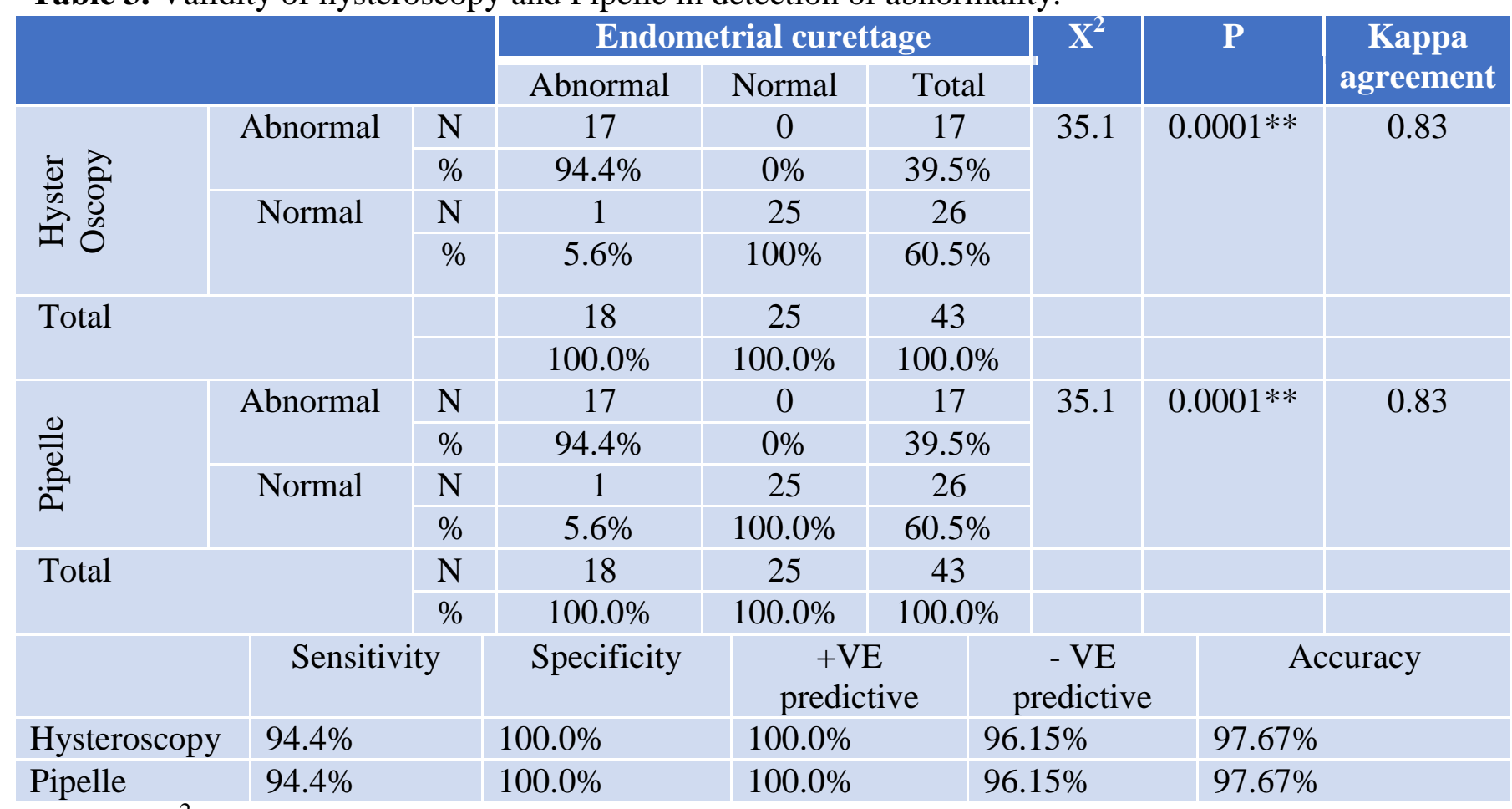
$\left(\mathrm{X}^{2}\right)$ : Chi square test.

Kappa: Agreement

$P$ value: was set at $<0.05$ for significant results \& $<0.001$ for high significant result. 
Table 4. Validity of hysteroscopy and Pipelle in detection of endometrial hyperplasia.

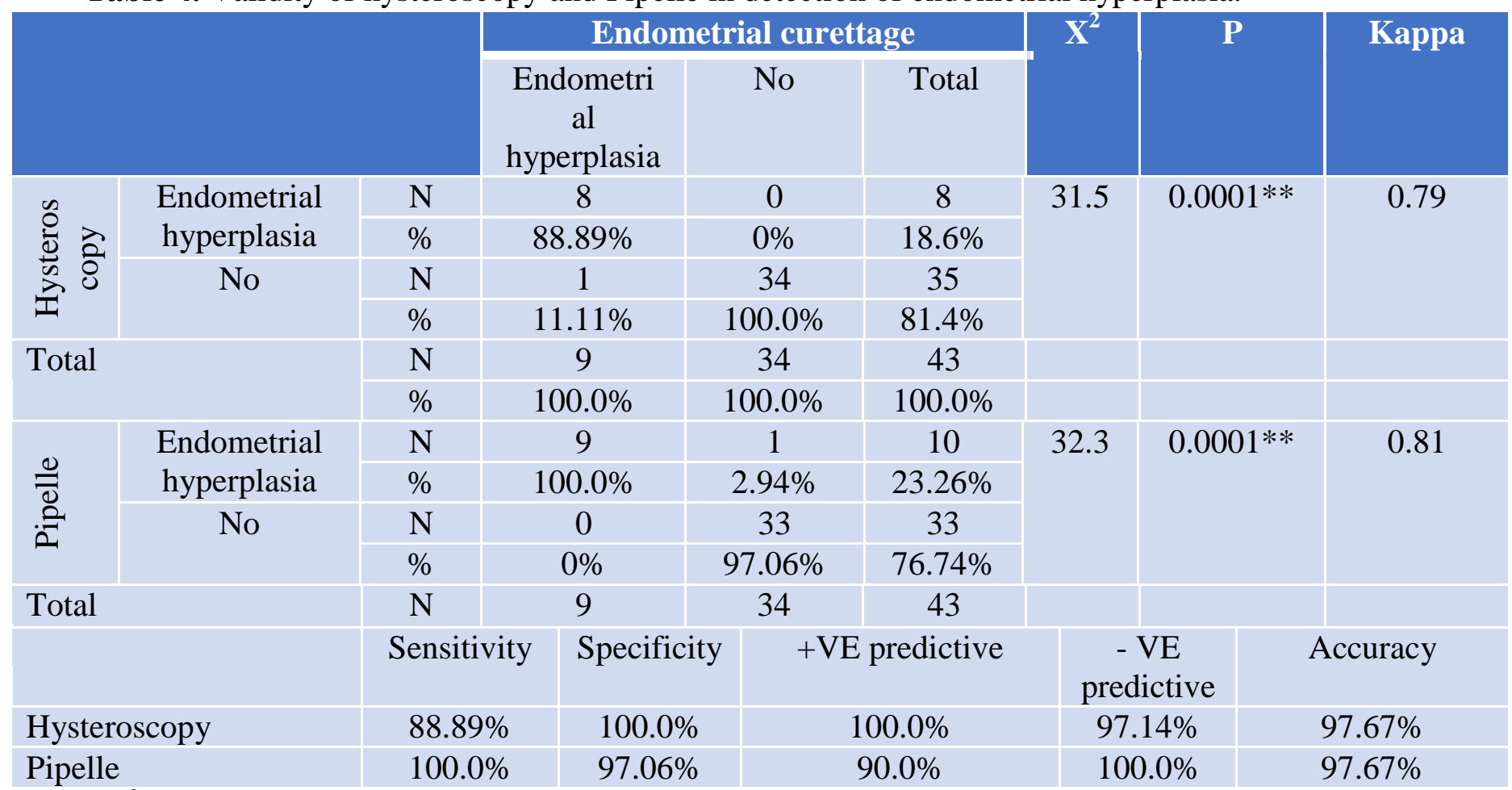

$\left(\mathrm{X}^{2}\right)$ : Chi square test.

Kappa: Agreement

P value: was set at $<0.05$ for significant results \& $<0.001$ for high significant result

Table 5. Validity of hysteroscopy and pipelle in detection of hyperplasia with atypia.

\begin{tabular}{|c|c|c|c|c|c|c|c|c|c|}
\hline & \multicolumn{3}{|c|}{ Endometrial curettage } & \multirow[t]{2}{*}{$\mathbf{X}^{2}$} & \multirow[t]{2}{*}{$\mathbf{P}$} & \multirow{2}{*}{$\begin{array}{c}\text { Kapp } \\
\mathbf{a}\end{array}$} \\
\hline & & & & $\begin{array}{l}\text { End. } \\
\text { Hyperplasia } \\
\text { with atypia }\end{array}$ & No & Total & & & \\
\hline \multirow{4}{*}{ 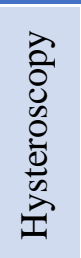 } & \multirow{4}{*}{\multicolumn{2}{|c|}{$\begin{array}{c}\text { End. } \\
\text { Hyperplasia } \\
\text { with atypia } \\
\text { No }\end{array}$}} & $\mathrm{N}$ & 2 & 0 & 2 & 14.9 & $0.0001 * *$ & 0.76 \\
\hline & & & $\%$ & $66.67 \%$ & $0 \%$ & $4.65 \%$ & & & \\
\hline & & & $\mathrm{N}$ & 1 & 40 & 41 & & & \\
\hline & & & $\%$ & $33.33 \%$ & $100.0 \%$ & $95.35 \%$ & & & \\
\hline \multirow[t]{2}{*}{ Total } & & & $\mathrm{N}$ & 3 & 40 & 43 & & & \\
\hline & & & $\%$ & $100.0 \%$ & $100.0 \%$ & $100.0 \%$ & \multirow{5}{*}{20.94} & \multirow{5}{*}{$0.0001 * *$} & \\
\hline \multirow{4}{*}{$\frac{\stackrel{0}{\overline{0}}}{\stackrel{2}{0}}$} & \multirow{2}{*}{\multicolumn{2}{|c|}{$\begin{array}{c}\text { End. } \\
\text { Hyperplasia } \\
\text { with atypia }\end{array}$}} & $\mathrm{N}$ & 3 & 1 & 4 & & & \multirow[t]{4}{*}{0.81} \\
\hline & & & $\%$ & $100.0 \%$ & $2.5 \%$ & $9.3 \%$ & & & \\
\hline & \multirow{2}{*}{\multicolumn{2}{|c|}{ No }} & $\mathrm{N}$ & 0 & 39 & 39 & & & \\
\hline & & & $\%$ & $0 \%$ & $97.5 \%$ & $90.7 \%$ & & & \\
\hline \multirow{3}{*}{\multicolumn{2}{|c|}{ Total }} & & $\mathrm{N}$ & 3 & 40 & 43 & & & \\
\hline & & & $\%$ & $100.0 \%$ & $100.0 \%$ & $100.0 \%$ & & & \\
\hline & & \multicolumn{2}{|c|}{ Sensitivity } & Specificity & \multicolumn{2}{|c|}{\begin{tabular}{|c|}
$+\mathrm{VE}$ \\
predictive
\end{tabular}} & $\begin{array}{c}\text { - VE } \\
\text { predictive }\end{array}$ & \multicolumn{2}{|c|}{ Accuracy } \\
\hline \multirow{2}{*}{\multicolumn{2}{|c|}{$\begin{array}{l}\text { Hysteroscopy } \\
\text { Pipelle }\end{array}$}} & \multirow{2}{*}{\multicolumn{2}{|c|}{$\begin{array}{l}66.67 \% \\
100.0 \%\end{array}$}} & \multirow{2}{*}{$\begin{array}{c}100.0 \% \\
97.5 \%\end{array}$} & \multirow{2}{*}{\multicolumn{2}{|c|}{$\begin{array}{c}100.0 \% \\
75.0 \%\end{array}$}} & $97.56 \%$ & \multicolumn{2}{|c|}{$97.67 \%$} \\
\hline & & & & & & & $100.0 \%$ & 97.6 & \\
\hline
\end{tabular}

$\left(\mathrm{X}^{2}\right)$ : Chi square test.

Kappa: Agreement

$P$ value: was set at $<0.05$ for significant results \& $<0.001$ for high significant result 
Table 6. Validity of hysteroscopy in detection of polyp.

\begin{tabular}{|c|c|c|c|c|c|c|c|c|}
\hline & \multicolumn{3}{|c|}{ Endometrial curettage } & \multirow[t]{2}{*}{$\mathrm{X}^{2}$} & \multirow[t]{2}{*}{$\mathbf{P}$} & \multirow[t]{2}{*}{ Kappa } \\
\hline & & & Polyp & No & Total & & & \\
\hline \multirow{4}{*}{$\begin{array}{l}\text { Hyster } \\
\text { oscopy }\end{array}$} & \multirow[t]{2}{*}{ Polyp } & $\mathrm{N}$ & 4 & 1 & 5 & \multirow[t]{4}{*}{29.9} & \multirow[t]{4}{*}{$0.001 * *$} & \multirow[t]{4}{*}{0.74} \\
\hline & & $\%$ & $100.0 \%$ & $2.56 \%$ & $11.63 \%$ & & & \\
\hline & \multirow[t]{2}{*}{ No } & $\mathrm{N}$ & 0 & 38 & 38 & & & \\
\hline & & $\%$ & $0 \%$ & $97.44 \%$ & $88.37 \%$ & & & \\
\hline \multirow[t]{3}{*}{ Total } & & $\mathrm{N}$ & 4 & 39 & 43 & & & \\
\hline & & $\%$ & $100.0 \%$ & $100.0 \%$ & $100.0 \%$ & & & \\
\hline & & tivity & \multicolumn{2}{|c|}{ Specificity } & $\begin{array}{c}+\mathrm{VE} \\
\text { predictive }\end{array}$ & \multicolumn{2}{|c|}{ - VE predictive } & Accuracy \\
\hline \multicolumn{2}{|l|}{ Hysteroscopy } & $.0 \%$ & \multicolumn{2}{|c|}{$97.44 \%$} & $80 \%$ & \multicolumn{2}{|c|}{$100.0 \%$} & $97.67 \%$ \\
\hline
\end{tabular}

$\left(\mathrm{X}^{2}\right)$ : Chi square test.

Kappa: Agreement

P value: was set at $<0.05$ for significant results \& $<0.001$ for high significant result

Table 7. Validity of hysteroscopy and Pipelle in detection of endometritis.

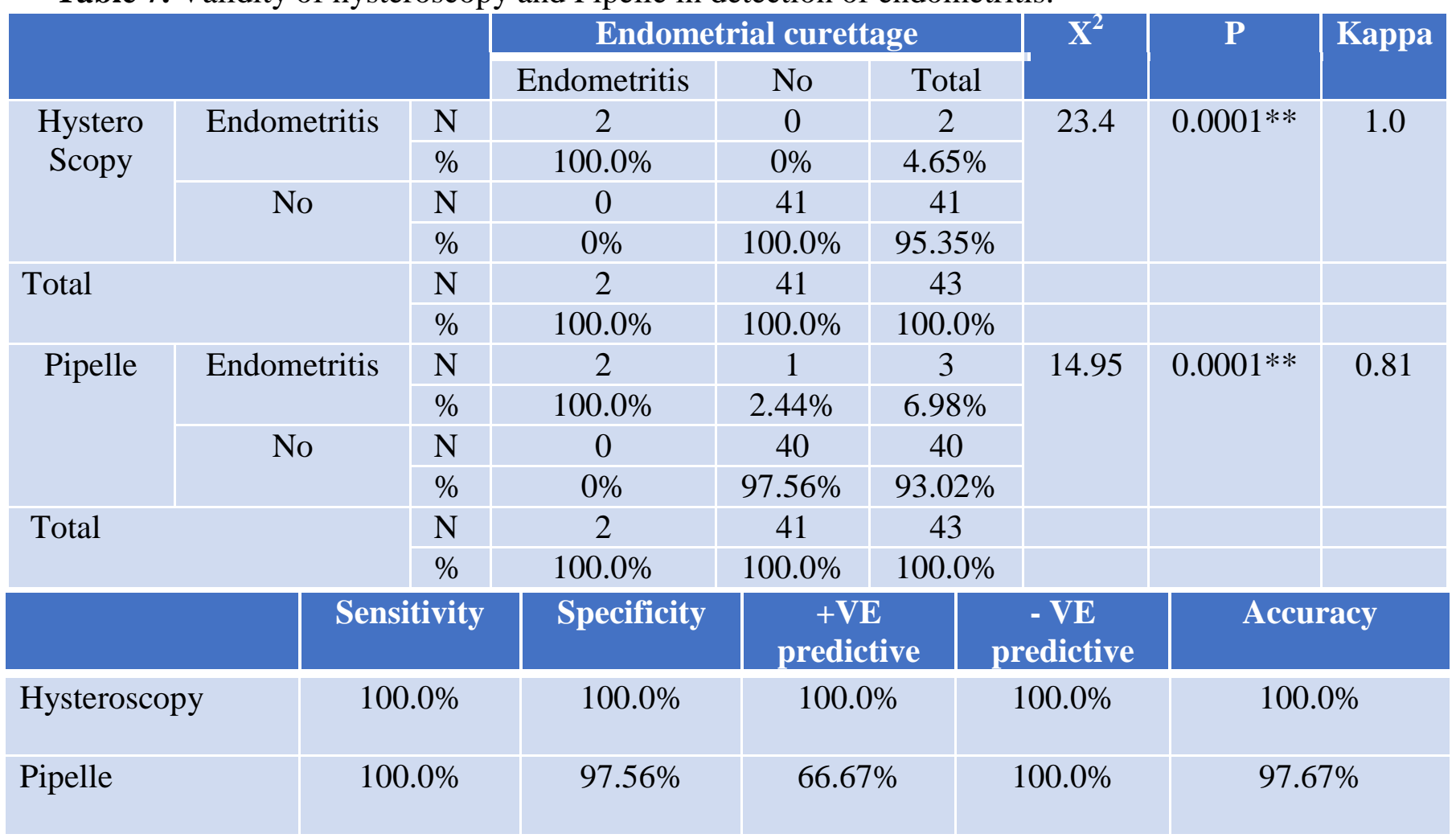

$\left(\mathrm{X}^{2}\right)$ : Chi square test.

Kappa: Agreement

$P$ value: was set at $<0.05$ for significant results \& $<0.001$ for high significant result. 


\section{DISCUSSION}

The present study was designed as a cross sectional study on $\leqslant r$ women who presented with perimenopausal bleeding attending at Zagazig university hospital outpatient clinics.

In present study, Regarding the distribution of the study population; the age was ranged from 42 to 53 years with a mean of $49.0 \pm 2.83$

In agreement with present study, Chandrakumari et al. [4] found that the mean age of the studied population was 44.6 years. Also the results were similar to Rauf et al. [8] as the mean age of the patients was $46.3 \pm 4.45$ years.

Regarding pathology of endometrial tissue obtained by D\&C and pipelle, the current study showed that the pathological findings of patient examined obtained by D\&C revealed abnormal in 18 cases (41.9\%), endometrial hyperplasia in 9 cases $(20.9 \%)$, hyperplasia with atypia in 3 cases $(6.95 \%)$, polyp in 4 cases $(9.3 \%)$, endometritis in 2 cases $(4.65 \%)$. While pipelle revealed abnormal in 17 cases (39.5\%) endometrial hyperplasia in 10 cases $(23.25 \%)$, hyperplasia with atypia in 4 cases $(9.3 \%)$, polyp in 0 cases $(0 \%)$,endometritis in 3 cases $(6.95 \%)$.This gives impression that endometrial hyperplasia is the commonest cause of peri-menpausal bleeding.

This was in accordance with Chandrakumari et al. [4], Liu et al. [9] who observed that the commonest cause of perimenpausal bleeding is endometrial hyperplasia

In agreement with our results, Alliratnam et al. [10] observed that polyp is rarely to be detected by pipelle.

On the contrary, Demirkiran et al. [11] found that the commonest lesion causing perimenopausal bleeding was focal lesions as endometrial polyp .

Regarding validity;this study showed good agreement between pipelle and D\&C in detection of endometrial abnormality. Pipelle had sensitivity $(94.4 \%)$ and specificity $(100.0 \%)$ in detection of endometrial abnormality.

This was in agreement with Alliratnam et al. [10] as they reported the sensitivity of pipelle sampling was 97 percent and the specificity was 100 percent when compared with D \& C sampling.

Abdelazim et al. [12] were also reported sensitivity higher than $90 \%$ for all pathological diagnoses except atrophic endometrium and also $100 \%$ specificity rate for all diagnoses which is similar to our findings.

Regarding validity of Pipelle and D\&C in different endometrial lesions, this study showed that in detection of endometrial hyperplasia, pipelle had sensitivity $(100.0 \%)$ and specificity (97.06\%), endometrial hyperplasia with atypia, pipelle had sensitivity (100.0\%) and specificity (97.5\%) polyp cannot be detected by pipelle. Regarding, endometritis , pipelle had sensitivity (100.0\%) and specificity $(97.56 \%)$.

This was in agreement with Sanam and Majid [13] who observed that Pipelle diagnostic accuracy in comparison with curettage, have been reported over $97 \%$, so the failure rate in this study was below $5 \%$.

On the other hand, the current study disagree with Demirkiran et al. [11] as they reported $67 \%$ sensitivity rate for pipelle biopsy in detection of endometrial hyperplasia which was lower than our study.

Regarding pathology of endometrial tissue obtained by D\&C and hysteroscopy, the current study showed that the pathological findings of patient examined obtained by D\&C revealed; abnormal in 18 cases (41.9\%), endometrial hyperplasia in 9 cases $(20.9 \%)$, hyperplasia with atypia in 3 cases(6.95\%),polyp in 4 cases (9.3\%) ,endometritis in 2 cases $(4.65 \%)$. While hysteroscopy revealed abnormal in 17 cases $(39.5 \%)$ endometrial hyperplasia in 8 cases $(18.6 \%)$, hyperplasia with atypia in 2 cases(4.65\%),polyp in 5 cases (11.6\%) ,endometritis in 2 cases $(6.95 \%)$. This gives impression that endometrial hyperplasia is the commonest cause of peri-menpausal bleeding.

This study agreed with a study done by El-Gamal et al. [14] who found that endometrial hyperplasia is the commonest cause of peri-menpausal bleeding.

In agreement with present study, Singh et al. [15] observed that polyp is usually detected by hysteroscopy. 
This study disagree with Garg et al. [16] who found that endometrial polyps were the most common cause of AUB.

Regarding validity; this study showed good agreement between hysteroscopy and $\mathrm{D} \& \mathrm{C}$ in detection of endometrial abnormality, hysteroscopy had sensitivity $(94.4 \%)$ and specificity $(100.0 \%)$ in detection of endometrial abnormality.

This was in agreement with El-Gamal et al. [14] as they reported that hysteroscopy had a sensitivity of $91.9 \%$, specificity of $86.5 \%$,

Regarding validity of hysteroscopy and $\mathrm{D} \& \mathrm{C}$ in different endometrial lesions. this study showed that in detection of endometrial hyperplasia. Hysteroscopy had sensitivity $(88.89 \%)$ and specificity (100.0\%), in endometrial hyperplasia with atypia, it had sensitivity $(66.67 \%)$ and specificity $(100.0 \%)$ in polyp ,it had sensitivity $(100.0 \%)$ and specificity $(97.44 \%)$. Regarding, endometritis, hysteroscopy had sensitivity $(100.0 \%)$ and specificity (100.0\%).

These results are being supported by Valson et al. [17] which showed Hysteroscopy diagnosed polyps, hyperplasia and sub mucosal myoma with $100 \%$ accuracy.

On the contrary, Garg et al. [16] showed that hysteroscopy in diagnosis of endometrial hyperplasia to have low accuracy, sensitivity, and specificity of $71 \%, 54.55 \%$, and $97.96 \%$, respectively, which was least among all pathologies.

In this study, there was a good agreement between hysteroscopy and pipelle in detection of endometrial abnormality and regarding sensitivity and specificity, pipelle and hysteroscopy had the same sensitivity $(94.4 \%)$ and specificity $(100.0 \%)$ in detection of endometrial abnormality compared to D\&C.

The same conclusion was reached by Saadia et al. [18] who's a study comparing hysteroscopy with Pipelle method, the sensitivity of hysteroscopy was found to be 94.4\% and Pipelle was found to be $97.5 \%$ for detection of endometrial lesions.

\section{CONCLUSION}

Pipelle endometrial sampling and hysteroscopy are an easy and safe methods of getting tissue diagnosis which can be done as an out-patient procedures and November. 2020 Volume 26 Issue 6 without anaesthesia. These methods are considered as effective as D\&C in evaluation of patients with abnormal uterine bleeding $(97.67 \%$ accuracy \& 0.83 agreement with D \& C ) with high sensitivity and specificity even for the detection of hyperplasia. However, large scale studies involving higher number of cases and variable age groups are required to support these data.

Conflict of Interest : Nothing to declare Financial Disclosures : Nothing to declare REFERENCES

1- Goldstein S. Modern evaluation of the endometrium. Obstet Gynecol. 2010; 116(1): 168-176.

2- Kotdawala P, Kotdawala S, Nagar N. Evaluation of endometrium in perimenopausal abnormal uterine bleeding. Journal of mid-life health. 2013; 4(1): 16.

3- Dogan E, Celiloglu M, Sarihan E. Anesthetic effect of intrauterine lidocaine plus naproxen sodium in endometrial biopsy. Obstet Gynecol. 2004; 103: 347.

4- Chandrakumari AS, lingappa HA, Singaravelu SD. Evaluation of Diagnostic Efficacy of Pipelle Endometrial Sampling in Abnormal Uterine Bleeding, Journal of Clinical and Diagnostic Research. 2018; 12(5): EC01-EC04.

5- Rasheed T. .Effectiveness of Pipelle as Endometrial Sampling Procedure in Comparison with Dilatation and Curettage. Journal of Rawalpindi Medical College. 2012; 16(2): 156-158.

6- Elbareg AM, Elmahashi MO, Essadi FM. Evaluation of intrauterine pathology: efficacy of diagnostic hysteroscopy in comparison to histopathological examination. Reprod Syst Sex Disord. 2015; 4(149): 2.

7- Singh P. Abnormal uterine bleedingevaluation by endometrial aspiration. $\mathrm{J}$ Midlife Health. 2018; 9(1): 32-35.

8- Rauf R, Shaheen A, Sadia S, Waqar F, Zafar $S$, Sultana $S$ et al. Outpatient endometrial biopsy with Pipelle versus diagnostic dilatation and curettage. J Ayub Med Coll Abbottabad. 2014; 26(2): 145-148.

9- Liu H, Wang FL, Zhao YM, Yao YQ, Li YL. Comparison of Pipelle sampler with conventional dilatation and curettage (D\&C) for Chinese endometrial biopsy, J Obstet Gynaecol. 2015; 35(5): 508-511.

10- Alliratnam AS, Senthil Priya S, Shankar R. Diagnostic value of Pipelle endometrial 
sampling in comparison with dilatation and curettage among patients with abnormal uterine bleeding. International Journal of Reproduction, Contraception, Obstetrics and Gynecology. 2016; 5(3): 865.

11- Demirkiran F, Yavuz E, Erenel H, Bese T, Arvas M, Sanioglu C. Which is the best technique for endometrial sampling? Aspiration (pipelle) versus dilatation and curettage (D\&C). Arch Gynecol Obstet. 2012; 286(5): 1277-1282.

12- Abdelazim IA, Aboelezz A, AbdulKareem AF. Pipelle endometrial sampling versus conventional dilatation \& curettage in patients with abnormal uterine bleeding. Journal of the Turkish German Gynecological Association. 2013; 14(1): 1.

13- Sanam M, Majid MM. Comparison the diagnostic value of dilatation and curettage versus endometrial biopsy by Pipelle-a clinical trial. Asian Pac J Cancer Prev. 2015; 16(12): 4971-4975.

14- El-Gamal HH, Abd-El-Salam MM, Ghanem RM, Al-Ani SI. Role of diagnostic hysteroscopy and histopathology in evaluation of abnormal uterine bleeding. The Egyptian Journal of Hospital Medicine. 2018; 72(7): 4765-4771.

15- Singh S, Taneja BK, Singh P, Ahlawat R. Role of diagnostic hysteroscopy in abnormal uterine bleeding. Int $\mathrm{J}$ Reprod Contracept Obstet Gynecol. 2014; 3(3): 544-551.

16- Garg G, Patvekar M, Agarwal K, Bhatia I, Sanghi S. A Study of the Role of Hysteroscopy in Abnormal Uterine Bleeding. Journal of Gynecologic Surgery 2017; 33(6): 226-230.

17- Valson H, Kulkarni C, Mukerjee S, Gowda $\mathrm{SN}$. The role of diagnostic hysteroscopy in abnormal uterine bleeding and its histopathological correlation following blind dilatation and curettage. Int $\mathrm{J}$ Reprod Contracept Obstet Gynecol. 2016; 5(3): 609614.

18- Saadia A, Mubarik A, Zubair A, Jamal S, Zafar A. Diagnostic accuracy of endometrial curettage in endometrial pathology. Journal of Ayub,Medical College, Abbottabad. 2011; 23: 129-131.

\section{Cite This Article - VANCOUVER Style}

Abd-Elmageed, A., abdo, A., el beheidy, T., Refaie, A. Office Hysteroscopy and Pipelle Endometrial Biopsy versus Diltation and Curettage in Diagnosis of Endometrial pathology in women with perimenopausal bleeding.. Zagazig University Medical Journal, 2020; (981-989): -. . doi: 10.21608/zumj.2019.15285.1371 